\title{
The Effect of Torsional Bending on Reliability and Lifetime of Printed Silver Conductors
}

\author{
Esa Hannila, Kari Remes, Timo Kurkela, Tuomas Happonen, Kimmo Keränen and Tapio Fabritius
}

\begin{abstract}
Capability of high speed and low-cost manufacturing makes the printing techniques very promising approach for largearea flexible electronics mass manufacturing. Due to fast and intensive technology development, the lack of knowledge about the reliability and lifetime of printed electronics is obvious, requiring further investigation. Especially, the effect of torsional bending on lifetime is mostly unexplored field of reliability testing. In this study, a torsional bending test of parallel printed silver conductors $(0.3 \mathrm{~mm}, 0.5 \mathrm{~mm}$ pitch) on polymer substrate (Polyethylene terephthalate, $125 \mu \mathrm{m}$ thickness) were conducted and analyzed. According to the experimental results, torsional bending causes wear-out type failures in conductors and the length-to-width (LTW) ratio of the sample's substrate was observed to have a significant impact on reliability. If the LTW ratio is smaller than 3 , the lifetime of printed conductor seems to collapse, and samples lasted for approximately only 17 bending cycles on average. Lifetime was improved by increasing the LTW ratio and samples withstood over hundreds of cycles with LTW ratio of higher than 15. However, the distance of a conductor from the edge of the substrate was not observed to have any significant influence on the reliability under torsional bending.
\end{abstract}

Index Terms-Printed electronics, flexible electronics, reliability testing, large area electronics, accelerated lifetime

\section{INTRODUCTION}

Since the days, when printing techniques were used mostly $\checkmark$ for graphical prints such as newspapers and books [1] the material and manufacturing techniques for printing have progressed remarkably [2]. Perhaps, the most intriguing type of exploitation for printing techniques is based on the utilization of electrically functional inks to fabricate electronics (conductors, semiconductors and dielectrics) with features (flexible stretchable, large-area, lightweight), which have not been feasible by conventional electronics. Electrically functional inks allows the fabrication of electronics components and even complete devices such as antennas [3], [4], sensors [5]-[8], memristors [9], diodes [10], [11], transistors [4], [12], LEDs [13], [14], solar cells and light detectors [15], [16]. Printing techniques have also been proven to be a very fast and efficient method to create large area electronics at very highvolume rates in mass production. As an additive manufacturing method, printing has distinctive benefits such as low manufacturing expenses and waste generation during the manufacturing [1], [17], [18].

Due to limited technological maturity of printed electronics,

This work is financially supported by Business Finland funded project (Dnro 3944/31/2014), Academy of Finland's FIRI funding (grant no. 320017) and European Regional Development Fund's Novel Digitally Fabricated Materials for Electronics, Optics and Medical Applications (grant no. A74080). conventional electronics components (regulators, microprocessors, LED chips etc.) are combined with printed electronics to improve the device performance. These types of devices are called as hybrid electronics in this context. Hybrid electronics has undergone fast technological development during past few years and the first products are emerging to the market including smart architectural elements and wearable electronics. [2], [19]

Once the materials, components and fabrication process with novel features are combined, the number of unknown parameters and the lack of knowledge on their influence on the device performance increases. For example, in the case of hybrid electronics, the characteristic and performance of rigid conventional components on flexible surface plays a crucial role in setting of new requirements for the electronics materials. Hence, the reliability of printed and hybrid electronics has become intensively researched subject. Many accelerated lifetime tests already exist to evaluate the effects of bending, stretching or temperature cycling to the lifetime and reliability of printed and hybrid electronics. [20]-[24] However, torsional bending, to which hybrid electronics will most likely be exposed during its lifetime, is mostly an unexplored field of research. There are only few articles about the topic in which the effect of cyclic and single bend or torsion on the functionality for single components is evaluated. [25], [26] These studies, however, are currently lacking the information about the factors that affect to the magnitude of the stress and how it could be reduced thus making designs for hybrid electronics more reliable.

In this study, the effects of torsional bending on flexible electronics reliability and lifetime are studied. A house made test system is utilized to conduct cyclic torsional bending to evaluate its influence on the resistance of printed conductors on flexible substrate and thus to their reliability. In addition, the location of conductors and the length-to-width (LTW) ratio of a sample's substrate was studied during the research to identify them as potential factors that influence on the magnitude of the stress during torsional bending.

\section{MATERIALS AND METHODS}

Reliability testing was performed for three different types of samples (depicted in Fig. 1.) to analyze the effect of LTW ratio on sample's reliability when exposed to torsional stress. There

E. Hannila, Optoelectronics and Measurement Techniques Research Unit, University of Oulu, Erkki Koiso-Kanttilan katu 3, 90570 Oulu, (email: esa.hannila@oulu.fi) 


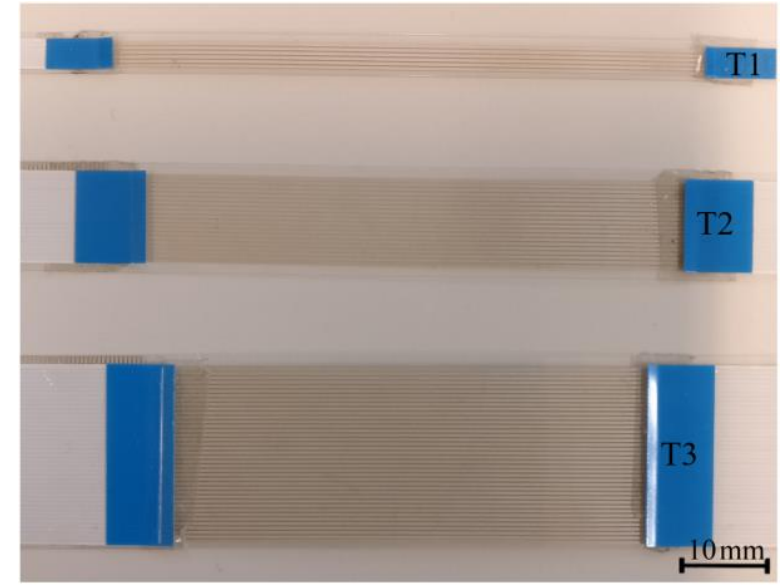

Fig. 1. Photograph of the printed conductors on PET film. The first sample type, the uppermost sample (T1) has six printed conductors of which all are measured. Second, the midmost sample type (T2) has 20 printed conductors of which six is evenly selected for measurement. The lowest, third sample type (T3) has 40 conductors. Only six is evenly chosen for measurement.

were ten pieces of each sample type in total to get reasonable amount of statistical data to perform a valid reliability analysis for the samples. All samples were measured before the actual reliability test to acquire reference values for their resistances. Resistance characteristics of the samples were measured during torsional bending and at the end of the test to double check that each sample were measured properly. More detailed description of the tested samples and their processing is explained in this chapter.

\section{A. Specifications of the used materials}

All tested samples had screen printed silver conductors on polyethylene terephthalate (PET) film with thickness of 125 $\mu \mathrm{m}$. In order to secure reliable galvanic contact to the conductors, each film with silver conductors had a surface mounted connector at the both ends (See Fig. 1.). All three sample types (T1, T2 and T3) were based on the same materials and identical printing process. Due to limited amount of inputs of the measuring system, only six conductors of each sample type were evenly chosen from T2 and T3 samples (See Fig. 12 ). The list of used materials and their technical details are summarized in Table I.

\section{B. Layout of the test patterns}

The layout of the conductor patterns consists of parallel, straight lines. Each individual conductor had pitch of $0.5 \mathrm{~mm}$

TABLE I

SPECIFICATIONS OF USED MATERIALS AND COMPONENTS

\begin{tabular}{|c|c|c|}
\hline Material/Component & Details & Comment \\
\hline Conductive tape & $3 \mathrm{M} 9703$ & $\begin{array}{l}\text { Anisotropically } \\
\text { conductive tape }\end{array}$ \\
\hline Conductive ink & Asahi LS-411AW & $\begin{array}{l}\text { Silver paste for } \\
\text { screen printing }\end{array}$ \\
\hline Connectors & $\begin{array}{l}\text { Series: WR-FCC } \\
\text { (Würth Electronics) }\end{array}$ & $\begin{array}{l}\text { Three variants: } 6,20 \\
\text { and } 40 \text { connections }\end{array}$ \\
\hline Foil & $\begin{array}{l}\text { Polyethylene } \\
\text { terephthalate (PET) }\end{array}$ & $\begin{array}{l}\text { Carrier film for } \\
\text { electronics }\end{array}$ \\
\hline Support epoxy & Loctite AA 3525 & Supporting epoxy \\
\hline
\end{tabular}

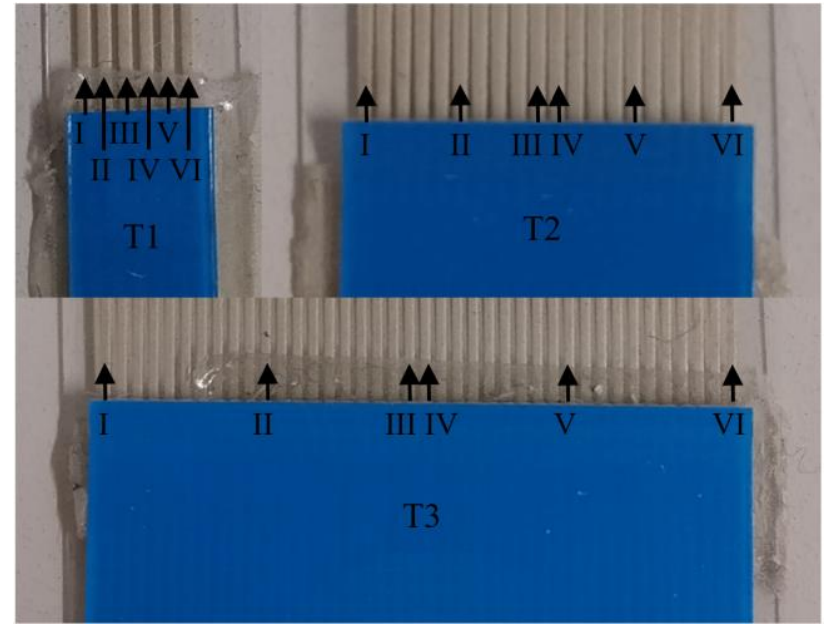

Fig. 2. Photograph of the printed conductors on PET film with pattern identification. Photograph also includes predefined conductors that are measured during torsional bending test to evaluate lifetime and reliability of the sample.

and linewidth of $0.3 \mathrm{~mm}$. T1 samples had six printed silver conductors, while the T2 and T3 samples had 20 and 40 conductors respectively. As mentioned before, each sample type (T1-T3) had a different LTW ratio due to the variating amount of the printed conductors. Table II. summarizes the key layout parameter of the conductors of each sample type.

\section{Fabrication process of the test patterns}

Fabrication process for the test patterns (A-J) per each sample types (T1-T3) utilized in the study had two main steps. At first, conductor patterns (Ag) were printed on a flexible and transparent PET film by utilizing a rotary screen-printing technique in a roll-to-roll process at the VTT premises in Oulu, Finland. Conductors were then post-processed with a proper heat treatment of 2 minutes at $120^{\circ} \mathrm{C}$ to cure the silver ink. Finally, standardized connectors were manually bonded (at the University of Oulu) on the printed conductors with anisotropically conductive tape. Connectors were also glued with UV-curable support epoxy to ensure that the connectors stay firmly attached to the conductors. Despite the sample type, only six conductors (I-VI) were chosen for the reliability test (see Fig. 2). The length of the different sample types also varied due to the original layout design of printed patterns. However,
TABLE II

PATTERN IDENTIFICATION AND DIMENSIONAL PARAMETERS

\begin{tabular}{ccccccc}
\hline \hline Type & $\begin{array}{c}\text { No. } \\
\text { conductors }\end{array}$ & Pitch & Linewidth & $\begin{array}{c}\text { Avg. } \\
\text { Length }\end{array}$ & $\begin{array}{c}\text { Avg. } \\
\text { Width }\end{array}$ & $\begin{array}{c}\text { Substrate } \\
\text { length-to- } \\
\text { width ratio }\end{array}$ \\
\hline T1 & 6 & $0.5 \mathrm{~mm}$ & $0.3 \mathrm{~mm}$ & $74.6 \mathrm{~mm}$ & $5.0 \mathrm{~mm}$ & 14.85 \\
T2 & 20 & $0.5 \mathrm{~mm}$ & $0.3 \mathrm{~mm}$ & $69.6 \mathrm{~mm}$ & $12.2 \mathrm{~mm}$ & 5.71 \\
T3 & 40 & $0.5 \mathrm{~mm}$ & $0.3 \mathrm{~mm}$ & $60.8 \mathrm{~mm}$ & $22.4 \mathrm{~mm}$ & 2.71 \\
\hline \hline
\end{tabular}




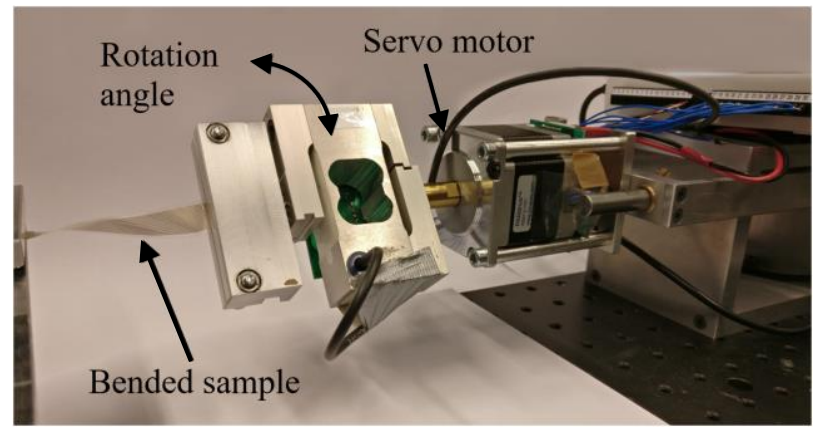

Fig. 3. Photograph of the testing system utilized in the study. One end of the sample is attached to system's clamp (on the right side of the figure), which is used to bend the sample.

measured values were expected to be comparable since the effect of variating length of the sample and conductors were taken into account by measuring the reference value before any torsional stress testing. It is worth to mention, that the resistance of a printed conductor is also highly dependable on the properties of the inks and post-processing parameters (drying and sintering) which were kept constant in this study.

\section{Torsional testing device}

Torsional bending is done with a house made testing system. The testing system is designed to conduct three reliability tests for flexible electronics. System can be utilized for tensional strength, bending and torsional testing of flexible samples. The system measures the sample as a function of time. In this study, the system was used only in the torsional testing mode.

Our measurement system consists of two electric step motors (see Fig. 3.). One motor is used to twist the sample freely and the other motor is used to change the distance between the clamps in order to compensate the sample shortening (and tensional stress) caused by the torsional bend. In practice the compensation is done by reducing the distance between the clamps during the torsional bend in order to minimize the tensional stress. System utilizes S2M-500 strain gauge-based load cell by HBM. The load cell is used to measure the tension applied to a sample (up to $50 \mathrm{~kg}$ ) during torsional bending. Tensional force is calculated according to Eq. 1 , where $F_{\text {nom }}$ is nominal force, $C$ is sensitivity, $U_{0}$ is excitation voltage and $U$ the measured voltage over the sensor. The device specification for sensitivity and nominal force are $2 \mathrm{mV} / \mathrm{V}$ and $500 \mathrm{~N}$.

$$
U=U_{0} C \frac{F}{F_{\text {nom }}}
$$

System control and measurement procedures are operated by a LabVIEW program. The program is used to measure conductors' resistance and to instruct the step motors together with the data from the load cell. USB-6211 data acquisition board by National Instrument is utilized as an interface between the computer and the test system. Test system's components are summarized in Table III.

\section{E. Failure criteria and mechanism}

Due to inks and used manufacturing process, printed conductors have lower conductivity than similar bulk
TABLE III

SPECIFICATIONS OF USED COMPONENTS

\begin{tabular}{lll}
\hline \multicolumn{1}{c}{ Component } & \multicolumn{1}{c}{ Details } & \multicolumn{1}{c}{ Comment } \\
\hline Motor 1 & $\begin{array}{l}\text { Trinamic PD57-2- } \\
1161 \\
\text { Trinamic PD86-3- }\end{array}$ & Stepper motor \\
Motor 2 & $\begin{array}{l}\text { Stepper motor } \\
\text { National Instrument, }\end{array}$ & $\begin{array}{l}\text { Data acquisition } \\
\text { board, interface for } \\
\text { DAQ-board }\end{array}$ \\
& NI USB-6211 & $\begin{array}{l}\text { PC } \\
\text { Load cell to } \\
\text { evaluate strain }\end{array}$ \\
Load cell & HBM, S2M-500 & \\
\hline \hline
\end{tabular}

conductors. In the case of printed silver, the conductivity is typically from $10 \%$ up to $56 \%$ from the corresponding value of bulk metal [27]. However, printed conductors withstand bending and stretching better than bulk metals. A common failure mechanism for a printed conductor during the bending is microfractures, causing an increase in its resistance due to a smaller local cross-sectional area according to Eq. 2 [24].

$$
R=\sum \rho \frac{l}{A}
$$

The bending of the sample, during the torsional stress, is expected to be negligible since the testing setup maintains the sample parallel to its torsional axis. In consequence of the nonaxisymmetric shape of the sample (rectangular cross-section), its shape does not remain planar and thus the stress and strain distribution become non-linear when exposed to torsion. For rectangular objects, the corners do not distort, and shear stresses are zero at those points. The maximum shear stresses are at the midpoints of the faces. Assuming the PET sample to be thin and isotropic rectangular, the analytical solutions for maximum stress $T_{\max }$ and torsion angle $\theta$ are as expressed in Eq. 3-4, where $\tau$ is torque, $L$ is the beam length, $W$ is the width, $\mathrm{t}$ is the thickness and $G$ is the shear modulus of the sample. Our testing device minimizes the tensile stresses by moving the other end of the sample. Thus, the stresses affecting the sample are expected to result only from the twisting and bending angle. [28]

$$
\begin{gathered}
T_{\max }=\frac{\tau}{\frac{1}{3} W t^{2}} \\
\theta=\frac{\tau L}{\frac{1}{3} W t^{3} G}
\end{gathered}
$$

Reliability tests require failure criteria, which define whether the sample passes the test or not [29]. In this experiment, a resistance measurement is conducted to evaluate the reliability of printed conductors. According to the standard IPC-9701, the sample which resistance increases $20 \%$ from its initial value during monotonic bending for six or more consecutive readings is considered as failed. In this study, the failure criteria defined in IPC-9701 were utilized.

The Weibull distribution is utilized to quantify the failure characteristics of torsionally stressed samples [30]. Failed 


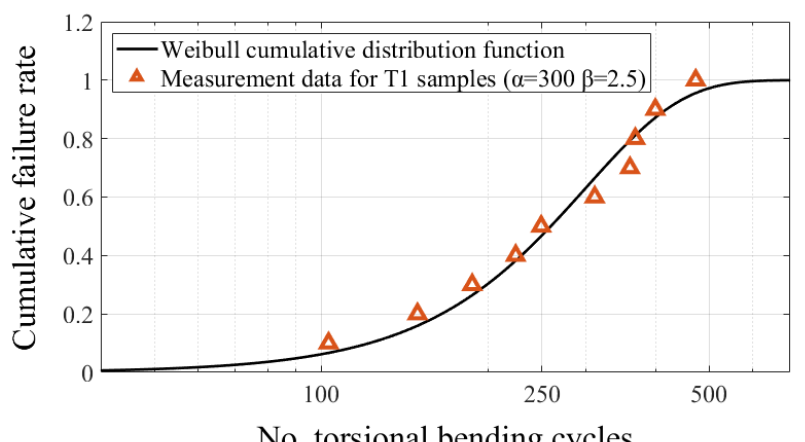

No. torsional bending cycles

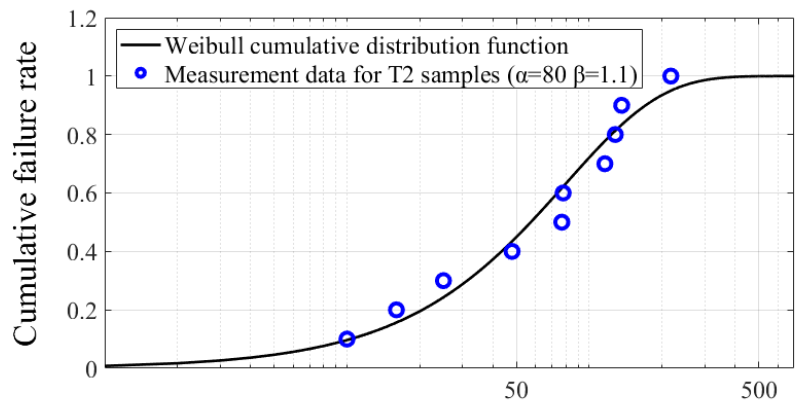

No. torsional bending cycles

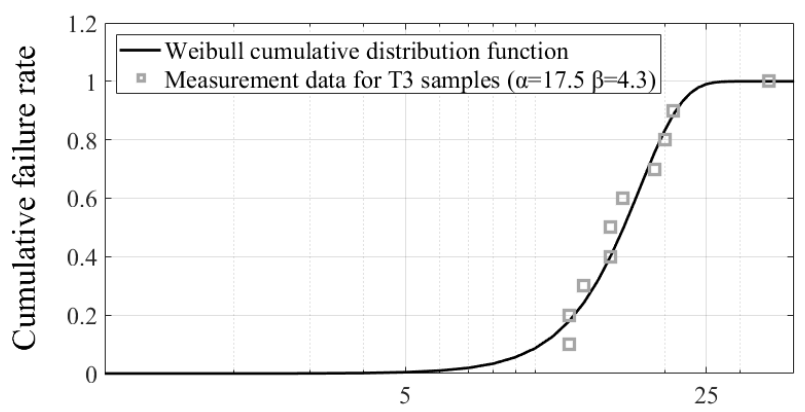

No. torsional bending cycles

Fig. 4. Weibull's cumulative failure distribution for each sample types (T1-T3) Samples are defined as failed when the resistance of each measured printed conductor has increased $20 \%$ of its initial value.

samples are presented in Weibull's cumulative distribution as a function to bending cycles according to Eq. 5, where $\alpha$ is scale parameter and $\beta$ is shape parameter. Scale parameter indicates the situation in which $62.5 \%$ of the test population have failed thus describing the characteristic lifetime of a test sample. Shape parameter describes the uniformity within the test sample population in regard to their lifetimes [30], [31].

$$
F(x)=1-e^{-(\alpha x)^{\beta}}, \text { for } x \geq 0
$$

\section{F. Torsional bending and resistance measurements}

The test samples are twisted clockwise and counterclockwise for 180 degrees during the test with angular speed of 950 degrees/min while measuring the resistance of the printed
TABLE IV

AVERAGE RESISTANCE AND STANDARD DEVIATION FOR SAMPLE TYPES

\begin{tabular}{ccccc}
\hline \hline Type & $\begin{array}{c}\text { Total no. } \\
\text { samples }\end{array}$ & $\begin{array}{c}\text { Total no. } \\
\text { conductors }\end{array}$ & $\begin{array}{c}\text { Avg. } \\
\text { resistivity }\end{array}$ & $\begin{array}{c}\text { Standard } \\
\text { deviation }\end{array}$ \\
\hline T1 & 10 & 60 & $7.62 \mathrm{e}-3 \Omega \mathrm{m}$ & $0.03 \%$ \\
T2 & 10 & 60 & $7.59 \mathrm{e}-3 \Omega \mathrm{m}$ & $0.03 \%$ \\
T3 & 10 & 60 & $7.85 \mathrm{e}-3 \Omega \mathrm{m}$ & $0.06 \%$ \\
\hline \hline
\end{tabular}

conductors using a four-point resistance measurement technique. Sampling rate for the resistance measurement is 1 Hz. Constant current is fed through the sample while voltage drop is being measured [32]. Knowing the voltage drop and the current over the sample, resistance can be calculated by Ohm's law [33].

In this study, we used a constant supply voltage and the current through each conductor was measured by utilizing a shunt resistor. Shunt resistors have resistance and tolerance value of $1 \Omega$ and $1 \%$ in order to minimize their impact on the measurement results. Samples are also clamped by the interface of connectors and printed conductors to eliminate stress at the interface. The resistance value for each individual conductor was then calculated from the measured current and constant supply voltage. The measurement data is filtered in order to find six consecutive readings when resistance is measured $20 \%$ higher than the initial resistance at initial state (at 0 degree) to define conductor as failed.

\section{G. Synchronized thermography}

Synchronized thermography is a characterization technique, which is based on synchronized electrical heating and IRimaging. It can be used for electrical uniformity analysis and determination of the defects of thin film electronics that would otherwise be very challenging or even invisible for other characterization techniques. Synchronized thermography has shown to be effective tool to maintain high process throughput yield in printed electronics manufacturing. [34]-[41]

In this study, a house made synchronized thermography system was used to analyze the irreversible effects of torsional stress on the structure and electrical characteristics of the printed conductors. The sample was heated for 15 seconds by a constant electric current of 200-800 mA depending on the sample and its type while being recorded into a video. Initially, the samples are in room temperature and they are recorded for

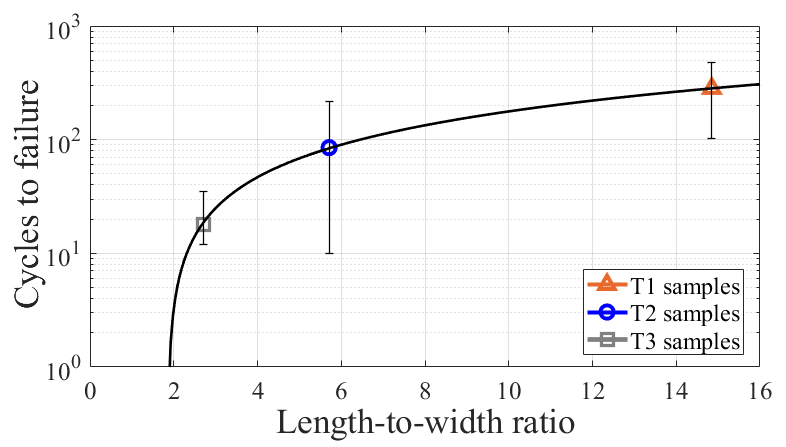

Fig. 5. Figure to express the effect of length-to-width ratio for sample durability against cyclic torsional bending thus affecting its reliability. 


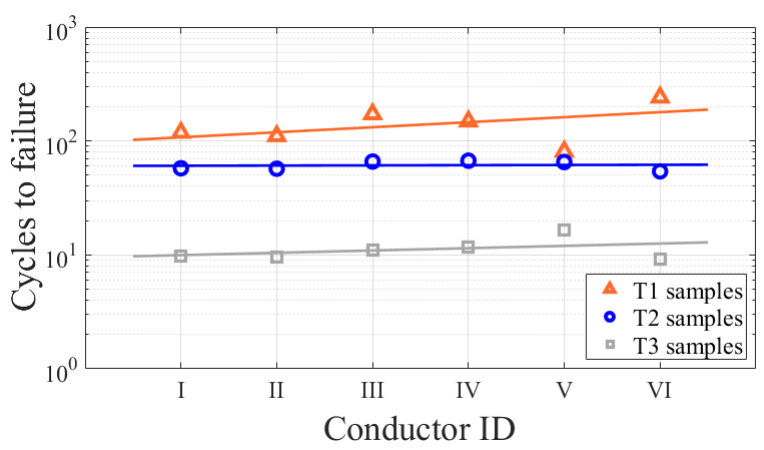

Fig. 6. Cycles to failure of printed conductors (I-VI) for each sample type. Figure shows how many torsional bending cycles it takes the conductor to fail to evaluate whether the magnitude of the stress is greater for different conductors.

5 seconds to get the reference values for post-processing of the measurement results. The samples are then heated with a constant heating current for 15 seconds until the current is switched off and the samples are let to cool down. Thermal images from the video are chosen as the measurement results with 5 second intervals at $5,10,15$ and 20 second.

\section{MEASUREMENT RESUlTS}

Reliability of printed conductors were analyzed by measuring its resistance continuously during the torsional bending.

\section{A. Resistance measurements}

Initial resistance of each printed conductor was measured as a reference value to define the failure criteria. Average initial resistivity values and standard deviation (STD) for different sample types are presented in Table IV. Three measurement values were discarded because of presumable loose electrical connection. The shape parameter in the Weibull analysis implies that there were some variations within the test population (see Fig. 4.). Variation in initial resistance was not considered to be critical for the reliability analysis because it can be taken into account in fault criteria determination by the measured reference value. Similar samples were investigated in previous article in which these types of variations were observed to be common for printed conductors [42].

Torsional bending causes wear-out type failures in printed

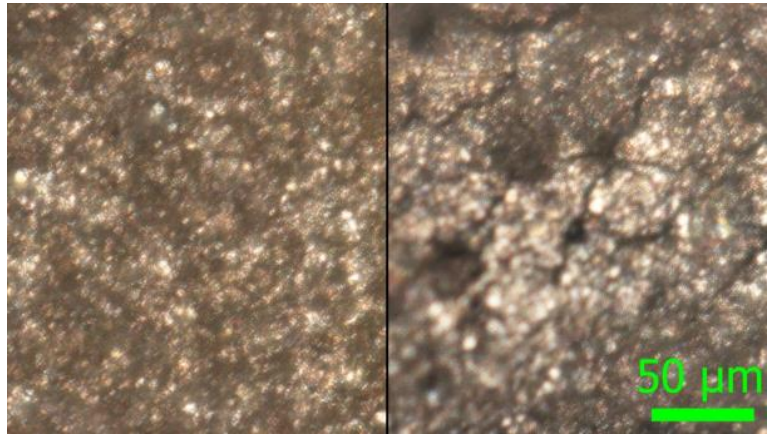

Fig. 8. The microscopy images of the printed silver conductor before and after the torsional bending (reference sample on the left). Microfractures are visible on the conductor caused by the exposure to torsional bending.

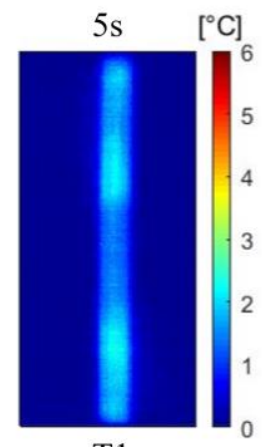

$\mathrm{T} 1$

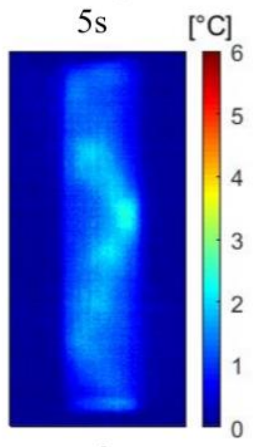

$\mathrm{T} 2$

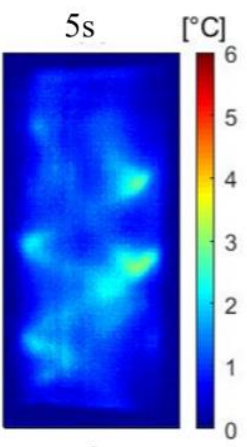

T3
Fig. 7. Photography from the thermography measurements from the samples. Almost every sample for each sample type had similar repetitive heat pattern. Each sample types had small variation but most sample had similar pattern.

conductors. Strain due to torsional bend creates microfractures in the conductor as depicted in Fig. 8. Due the low thickness of a printed conductor, even small defects can have significant effect on the conductivity. However, more detailed failure mechanism explanation requires further investigation.

According to results, the magnitude of the stress during the bend greatly depends on the LTW ratio (see Table II. and Fig. 5.). The T3 samples had the lowest average LTW ratio and were the most vulnerable for torsional bending enduring only 35 cycles until each sample was failed (see Fig. 4-5.). The T2 samples had higher average LTW ratio and they endured 217 cycles, which was over 6-times more cycles compared to the T3 samples. The T1 samples had the highest average LTW ratio and were the most durable sample type. The T1 samples lasted for 473 cycles, which is approximately 13,5-times more than for the T3 samples. In other words, the lower the LTW ratio, the higher the stress caused by the torsional bending is. This is also supported by the Weibull distribution in which the T1 samples had the highest scale parameter, the $\mathrm{T} 2$ had the second highest and the T3 the lowest scale parameter (see Fig. 4).

To analyze if the location of the conductor has an influence on the reliability, the effect of torsional bending on individual conductor was investigated (see Fig. 6.). According to the measurement, conductor's distance from the edge of the substrate does not significantly influence on its reliability and conductors did not fail in distinctive, repetitive order. Instead, the stress seemed to distribute on all conductors and defects appeared sequentially.

\section{B. Synchronized thermography measurements}

Synchronized thermography measurement results are shown in Fig. 7. According to images of different sample types, torsional stress causes clear non-uniformities in the resistance of printed conductors (See Fig. 7.). Especially in the case of the $\mathrm{T} 2$ and $\mathrm{T} 3$ samples, the heating patterns were observed to have a wave-shaped form over the whole wideness of the samples, correlating well with the observation that the distance of the conductor from the edge of the substrate has only minor influence on its reliability. The sample type T3 has the strongest heat spots, which might be caused by the observed irreversible folding during the bending. These irreversible deformations were clearly visible to human eye. 


\section{Discussions}

Torsional bending causes wear-out type defects inside the structure of a printed conductor. Cyclic bending wears the conductors resulting in microfractures and increased resistances. According to our measurements, the effect of cyclic torsional bending is similar for each sample, but its magnitude variates depending on samples' properties (see Fig. 4.-5. and Fig. 7.).

Initial resistance was measured as a reference value for the samples. Small variations were observed in the initial resistances of the samples. Dominant source for the variations is the printing process and its quality but two interfaces between the printed conductors and the connectors might cause variations as well. Inaccuracies of the manufacturing process may appear in length, in cross-sectional area of a printed conductor and in the conductivity of the ink. However, the variations in initial resistances were tolerable for each sample. Small variations were also a less critical aspect during the research because the initial resistance was utilized to define the $20 \%$ increase in the resistance and failed samples.

Samples' LTW ratio influenced their reliability and lifetime under cyclic torsional bending (see Fig 4.-5.). The T3 samples were the shortest and widest type thus they had the lowest LTW ratio and were the most vulnerable to bending. They also had the lowest scale parameter and endured 35 bending cycles until each sample filled the failure criterion. The $\mathrm{T} 2$ samples had a higher LTW ratio and scale parameter than the T3 samples making them more resilient against the torsional bending. The T2 samples lasted 217 bending cycles until each sample had failed. The T1 sample had the highest LTW ratio and highest scale parameter. They were the most resilient against the torsional bending with 473 bending cycles until each sample had failed. According to the results, it is obvious that the LTW ratio influences greatly on the sample's durability against torsional bending. The higher the LTW ratio is the more reliable the sample is.

Tensile stresses are minimized during the test and their influence on reliability can be neglected in our experiments. Hence, the main source of stress is expected to be the twisting along and the bending on the perpendicular axis with respect to the torsional axis during the test. According to Eq. 3.-4. torque depends on the sample geometry and the torsion angle. A wider and shorter sample requires more torque to be twisted than a long and narrow sample. Higher torque is directly proportional to higher maximum stress, supporting the observation for LTW ratio's influence on the reliability of the samples. Additionally, the higher the width of the samples is, the steeper the perpendicular bending angles becomes resulting in higher stresses and increased failure rates. Observed measurement results suggest that if the LTW ratio is smaller than 3 the reliability of a printed conductor collapses. This could be essential information when designing i.e. power supply lines for printed and hybrid electronics, since it is often required to be implemented as multiple parallel printed conductor due current limitations for a single conductor.

We also studied whether the magnitude of the stress caused by torsional bending variates depending on the location of the conductor on a substrate. Hence, the resistance was measured from multiple parallel conductor to observe if conductors would fail in a certain, repetitive order. According to our resistance measurements, the distance between the conductor and the edge of the substrate did not affect on its reliability (see Fig. 6.) even though the defects appeared sequentially.

Mere resistance measurement was not comprehensive technique enough to obtain accurate and detailed data about the stress distribution. Hence, a synchronized thermography was utilized to localize defects and visualize the stress distribution on the samples. According to the thermal images, the stress for the T1 samples was almost thoroughly constant and only in the middle of the sample the stress was a little bit lower. Structural defects were visible in thermal images at the both ends of the printed conductors near the connector interfaces. For the T2 samples, there was a distinct fluctuating, wave-like heat pattern, indicating that the stress distribution is not even but will distribute along the sample in a fluctuating form. The T3 samples had a similar but denser fluctuating heat pattern than the T2 samples implying that the stress caused by the bending is similar. In addition to fluctuating pattern, the T3 samples had extra heat spots making the pattern a bit less visible for some samples. On the other hand, as stated, the T3 samples were observed to fold during the torsional bending. Sharp folding creates fractures in the conductors of the T3 sample affecting on their resistance more quickly than wear-out type defects does on the resistance of the T1 and T2 samples. One explanation for the waviness of heat pattern could be the bending on perpendicular axis during the torsion. Simulation model could be utilized alongside with synchronized thermography images to evaluate the stress distribution even further.

From the commercial exploitation point of view, it is important to gain knowledge about the reliability and lifetime for printed conductors on flexible substrate under mechanical stress caused by torsional bending. It is also important to identify and understand what factors influence to the magnitude of the stress. In addition to LTW ratio and the torsional bending angle, different materials for the substrate and inks as well as thickness of the substrate are known to have an influence on the sample reliability under cyclic bending. However, their detailed influence in sample reliability during the torsional bending requires further investigation. These results guide the electronic designer to make layouts which are less vulnerable for torsional stress.

\section{CONCLUSION}

Torsional bending causes wear-out type defects in printed conductor. The LTW ratio of a sample's substrate in fact has a significant effect to sample's reliability. The lower the LTW ratio is, the higher the magnitude of the stress and more vulnerable is the sample against torsional bending. Hence, the reliability of the printed conductors on a flexible substrate can be improved by proper layout design. The location of a printed conductor on a substrate did not influence on its reliability regardless of the LTW ratio of the sample. Heat patterns from synchronized thermography measurements indicated that the stress distribution of the torsional bending is not even and has a 
fluctuating, wave-like pattern distributed along the samples with a lower LTW ratio. As summarized design guideline, it is important to keep the LTW ratio higher than 3 to avoid a drastic decrement of reliability. However, the location for printed conductor is not as critical. The gained knowledge and expertise provide guidance for designing the flexible hybrid electronics devices suitable for commercial products.

\section{ACKNOWLEDGMENT}

This work is financially supported by Business Finland funded project (Dnro 3944/31/2014), Academy of Finland's Printed intelligence infrastructure (grant no. 320017) and European Regional Development Fund's Novel Digitally Fabricated Materials for Electronics, Optics and Medical Applications (grant no. A74080)

\section{REFERENCES}

[1] Y. Neuvo and S. Ylönen, "Bit bang: Rays to the future," Espoo, Helsinki University of Technology, 2009, pp. 66-69.

[2] Z. Fan et al., "Toward the Development of Printable Nanowire Electronics and Sensors," Advanced Materials, vol. 21, no. 37, pp. 3730-3743, 2009. DOI: 10.1002/adma.200900860.

[3] V. Subramanian et al., "Progress Toward Development of All-Printed RFID Tags: Materials, Processes, and Devices," Proceedings of the IEEE, vol. 93, no. 7, pp. 1330-1338, 2005. DOI: 10.1109/JPROC.2005.850305 .

[4] V. Subramanian, P. Chang, J. Lee, S. Molesa and S. Volkman, "Printed organic transistors for ultra-low-cost RFID applications," IEEE Transactions on Components and Packaging Technologies, vol. 28, no. 4, pp. 742747, 2005. DOI: 10.1109/TCAPT.2005.859672.

[5] J.-V. Voutilainen, T. Happonen, J. Hakkinen and T. Fabritius, "All silk-screen printed polymer-based remotely readable temperature sensor," IEEE Sensors Journal, vol. 15, no. 2, pp. 723-733, 2015. DOI: 10.1109/JSEN.2014.2350077.

[6] J. Kukkola et al., "Novel printed nanostructured gas sensors," Procedia Engineering, vol. 25, pp. 896-899, 2011. DOI: 10.1016/j.proeng.2011.12.220.

[7] J.-V. Voutilainen, T. Happonen, J. Häkkinen and T. Fabritius, "Screen-Printed Remotely Readable Environmental Sensor Pair," IEEE Sensors Journal, vol. 16, no. 10, pp. 3523-3531, 2016. DOI: 10.1109/JSEN.2016.2532383.

[8] K. Jokinen et al., "Performance Enhancement of Polymer Electrolyte MEIS Hydrogen Sensor by DCBiasing," IEEE Sensors Journal, vol. 16, no. 13, pp. 5292-5297, 2016. DOI: 10.1109/JSEN.2016.2561318.

[9] P. Vilmi et al., "Fully printed memristors for a selfsustainable recorder of mechanical energy," Flexible and Printed Electronics, vol. 1, no. 2, 2016. DOI: 10.1088/2058-8585/1/2/025002.
[10] P. Kopola, M. Tuomikoski, R. Suhonen and A. Maaninen, "Gravure printed organic light emitting diodes for lighting applications," Thin Solid Films, vol. 517, no. 19 , pp. 5757-5762, 2009. DOI: 10.1016/j.tsf.2009.03.209.

[11] S. Bade et al., "Fully Printed Halide Perovskite LightEmitting Diodes with Silver Nanowire Electrodes," ACS Nano, vol. 10, no. 2, pp. 1795-1801, 2016. DOI: 10.1021/acsnano.5b07506.

[12] S. Kim et al., "Electrolyte-gated transistors for organic and printed electronics," Advanced Materials, vol. 25, no. 13, pp. 1822-1846, 2013. DOI: 10.1002/adma.201202790.

[13] M.-C. Choi, Y. Kim and C.-S. Ha, "Polymers for flexible displays: From material selection to device applications," Progress in Polymer Science, vol. 33, no. 6, pp. 581-630, 2008. DOI: 10.1016/j.progpolymsci.2007.11.004.

[14] S. Ummartyotin, J. Juntaro, M. Sain and H. Manuspiya, "Development of transparent bacterial cellulose nanocomposite film as substrate for flexible organic light emitting diode (OLED) display," Industrial Crops and Products, vol. 35, no. 1, pp. 92-97, 2012. DOI: 10.1016/j.indcrop.2011.06.025.

[15] F. Krebs, "Fabrication and processing of polymer solar cells: A review of printing and coating techniques," Solar Energy Materials and Solar Cells, vol. 93, no. 4, pp. 394-412, 2009. DOI: 10.1016/j.solmat.2008.10.004.

[16] R. Sliz et al., "Ink formulation for inkjet-printed colloidal quantum dots-based efficient infrared detectors," ACS Nano, vol. (Accepted), 2019.

[17] D. Thomas, "Costs, benefits, and adoption of additive manufacturing: a supply chain perspective," International Journal of Advanced Manufacturing Technology, vol. 85, no. 5-8, pp. 1857-1876, 2016. DOI: 10.1007/s00170-015-7973-6.

[18] F. Hoeng, A. Denneulin and J. Bras, "Use of nanocellulose in printed electronics: A review," Nanoscale, vol. 8, no. 27, pp. 13131-13154, 2016. DOI: $10.1039 / \mathrm{c} 6 \mathrm{nr} 03054 \mathrm{~h}$.

[19] Y. Khan et al., "Flexible Hybrid Electronics: Direct Interfacing of Soft and Hard Electronics for Wearable Health Monitoring," Advanced Functional Materials, vol. 26 , no. 47 , pp. $8764-8775,2016$. DOI: 10.1002/adfm.201603763.

[20] T. Happonen, J. Häkkinen and T. Fabritius, "Cyclic bending reliability of silk screen printed silver traces on plastic and paper substrates," IEEE Transactions on Device and Materials Reliability, vol. 15, no. 3, pp. 394401, 2015. DOI: 10.1109/TDMR.2015.2457231.

[21] T. Happonen, T. Ritvonen, P. Korhonen, J. Häkkinen and T. Fabritius, "Modeling the Lifetime of Printed Silver Conductors in Cyclic Bending with the Coffin Manson relation," IEEE Transactions on Device and Materials Reliability, vol. 16, no. 1, pp. 25-29, 2016. DOI: 10.1109/TDMR.2015.2507619. 
[22] T. Happonen, J.-V. Voutilainen, J. Häkkinen and T. Fabritius, "The effect of width and thickness on cyclic bending reliability of screen printed silver traces on a plastic substrate," IEEE Transactions on Components, Packaging and Manufacturing Technology, vol. 6, no. 5, pp. 722-728, 2016. DOI:

10.1109/TCPMT.2016.2544441.

[23] S.-M. Yi, I.-S. Choi, B.-J. Kim and J. Y-C, "Reliability Issues and solutions in Flexible Electronics Under Mechanical Fatigue," Electronic Materials Letters, vol. 14 , no. 4, pp. 387-404, 2018. DOI: 10.1007/s13391-0180043-0.

[24] M. Li et al., "Liquid metal-based electrical interconnects and interfaces with excellent stability and reliability for flexible electronics," Nanoscale, vol. 11, no. 12, pp. 5441-5449, 2019. DOI: 10.1039/c8nr09503e.

[25] S.-M. Sim et al., "RF performance of ink-jet printed microstrip lines on rigid and flexible substrates," Microelectronic Engineering, vol. 168, pp. 82-88, 2017. DOI: 10.1016/j.mee.2016.11.011.

[26] M. Finn et al., "Mechanical stability of roll-to-roll printed solar cells under cyclic bending and torsion," Solar Energy Materials and Solar Cells, vol. 174, pp. 715, 2018. DOI: 10.1016/j.solmat.2017.08.015.

[27] J. Perelaer, A. De Laat, C. Hendriks and U. Schubert, "Inkjet-printed silver tracks: Low temperature curing and thermal stability investigation," Journal of Materials Chemistry, vol. 18, no. 27, pp. 3209-3215, 2008. DOI: 10.1039/b720032c.

[28] G. Maddux, L. Vorst, F. Giessler and T. Moritz, "Stress Analysis Manual," United States Government Publishing Office, Dayton, 1969.

[29] H. Qi, N. Vichare, M. Azarian and M. Pecht, "Analysis of solder joint failure criteria and measurement techniques in the qualification of electronic products," IEEE Transactions on Components and Packaging Technologies, vol. 31, no. 2, pp. 469-477, 2008. DOI: 10.1109/TCAPT.2008.921647.

[30] H. Cui, "Accelerated temperature cycle test and CoffinManson model for electronic packaging," in Proceedings - Annual Reliability and Maintainability Symposium, Alexandria, 2005. DOI: 10.1109/RAMS.2005.1408421.

[31] R. Barlow and F. Proschan, Statistical theory of reliability and life testing : probability models, New York: NY: Holt, Rinehart and Wisnston, 1975.

[32] S. Thorsteinsson et al., "Accurate microfour-point probe sheet resistance measurements on small samples," Review of Scientific Instruments, vol. 80, no. 5, p. 053902, 2009. DOI: 10.1063/1.3125050.

[33] J. W. Nilsson and S. A. Riedel, Electric Circuits, Harlow: Pearson Education Limited, 2015.

[34] R. Usamentiaga, P. Venegas, J. Guerediaga, L. Vega, J. Molleda and F. Bulnes, "Infrared thermography for temperature measurement and non-destructive testing,"
Sensor, vol. 14, no. 7, pp. 12305-12348, 2014. DOI: 10.3390/s140712305.

[35] A. Katunin, K. Dragan and M. Dziendzikowski, "Damage identification in aircraft composite structures: A case study using various non-destructive testing techniques," Composite Structures, vol. 127, pp. 1-9, 2015. DOI: 10.1016/j.compstruct.2015.02.080.

[36] D. Titman, "Applications of thermography in nondestructive testing of structures," NDT \& $E$ International, vol. 34, no. 2, pp. 149-154, 2001. DOI: 10.1016/S0963-8695(00)00039-6.

[37] K. Leppänen, J. Saarela and T. Fabritius, "IR-imaging based system for detecting the defects of conductive materials," Proceedings of SPIE - The International Society for Optical Engineering, vol. 9205, no. Article number 92050M, 2014. DOI: 10.1117/12.2060834.

[38] K. Remes, A. Järvenpää and T. Fabritius, "Contactless online characterization of large-area conductive thin films by thermography and induction," Optics Letters, vol. 44, no. 10 , pp. 2574-2577, 2019. DOI: 10.1364/OL.44.002574.

[39] C. Schuss, K. Remes, K. Leppanen, J. Saarela, T. Fabritius, B. Eichberger and T. Rahkonen, "Detecting Defects in Photovoltaic Panels With the Help of Synchronized Thermography," IEEE Transactions on Instrumentation and Measurement, vol. 67, no. 5, pp. 1178 - 1186, 2018. DOI: 10.1109/TIM.2018.2809078.

[40] K. Leppänen, J. Saarela, R. Myllylä and T. Fabritius, "Electrical heating synchronized with IR imaging to determine thin film defects," Optics Express, vol. 21, no. 26, pp. 32358-32370, 2013. DOI: 10.1364/OE.21.032358.

[41] K. Remes, K. Leppänen and T. Fabritius, "Thermography based online characterization of conductive thin films in large-scale electronics fabrication," Optics Express, vol. 26, no. 2, pp. 12191229, 2018. DOI: 10.1364/OE.26.001219.

[42] E. Hannila, B. Augustine, T. Kurkela, J. Lauri and T. Fabritius, "Yield and Electrical Functionality of the Glass Laminated Conductive Wires and Connectors," IEEE Transactions on Components, Packaging and Manufacturing Technology, vol. 9, no. 12 , pp. 24992505, 2019. DOI: 10.1109/TCPMT.2019.2923858.

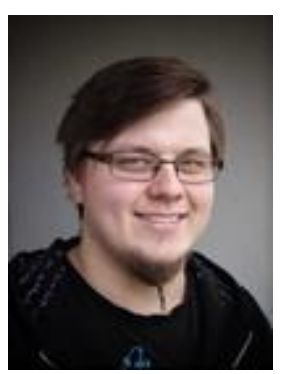

Esa Hannila received the M. Sc. degree and Doctoral study rights from University of Oulu, Oulu, Finland, in 2018. He has started working in the University of Oulu in 2017. He currently works in the research unit of Optoelectronics and Measurement Techniques as postdoctoral student. His current research interests involve reliability testing, multiphysics simulations and development for printed intelligence and additive manufacturing methods. 


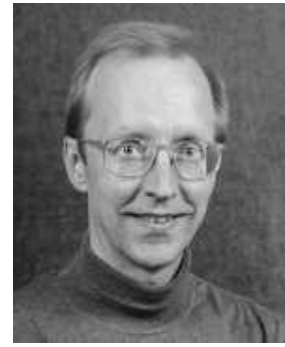

Kari Remes received the M.Sc. degree from the University of Oulu, Oulu, Finland, in 1991. Since 1992, he has been holding several research and development positions at different units of the University of Oulu, where he is currently a Project Manager with the Optoelectronics and Measurement Techniques Research Unit. His current research interests include online-compatible measurement and characterization techniques - especially thermography based ones - applied to printed electronics.

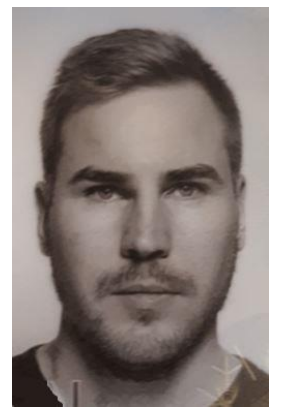

Timo Kurkela work as research scientist at Technical Research Centre of Finland (VTT) in Oulu. He has received his Bachelor of Science degree from Faculty of Science in University of Oulu majoring in physics in 2013 and Master of Science degree from Faculty of information Technology and Electrical engineering in University of Oulu majoring in microsystems technology in 2016. He is currently part of the flexible electronics integration team and his research interest includes hybrid electronics design and system integration.

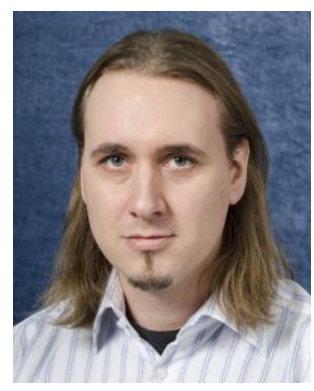

Tuomas Happonen received M.Sc. (Tech), Lic.Sc. (Tech) and D.Sc. (Tech) degrees in Electrical Engineering from the University of Oulu, Finland, in 2005, 2008 and 2016, respectively. From 2004 to 2016 he worked in research and teaching staff of Optoelectronics and Measurement Techniques research unit at the University of Oulu. At that time, his research work concentrated on reliability testing of printed electronics, especially on cyclic bending tests of printed conductors on flexible substrates. Since 2016 he has been working as a Senior Scientist in Flexible Electronics Integration research team at VTT. His current research interests include roll-to-roll functional testing and roll-to-roll assembly of printed and hybrid electronics as well as their reliability.

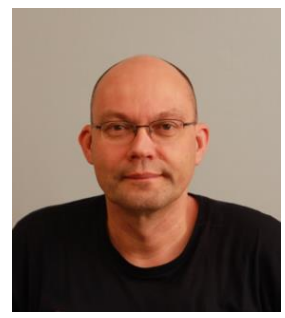

Kimmo Keränen received his MSc, Lic. Sc. and D. Sc (Tech.) degrees in electrical engineering from University of Oulu, Finland in 1992, 2002 and 2008, respectively. He is a Senior Scientist in Flexible Electronics Integration at VTT. His current research interests are in the field of photonic module and system integration based on flexible substrates. He is especially interested in building up versatile functionalities on flexible substrates utilizing semiconductor devices/components and hybrid integration technologies. Specific application area is large area lighting/display systems based on printed plastic substrates equipped with LEDs a in roll-to-roll manufacturing. He is author and coauthor of over 20 journal papers and over 30 conference papers. He is a deputy board member of Photonics Finland and member of European Optical Society.

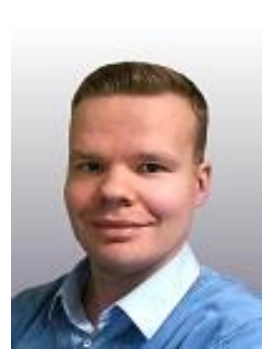

Tapio Fabritius received the M.Sc. and D.Sc. degrees (applied electronics) engineering from the University of Oulu, Oulu, Finland, in 2003 and 2007, respectively.

He has been with the University of Oulu since 2003, where he is currently a full Professor and the head of the Optoelectronics and Measurement Techniques Research Unit. His current research interests include the development of instrumentation and printed intelligence manufacturing technologies. He has published more than 60 peer-reviewed papers in reputed journals. 